\title{
Fiscal Impacts of Demographic Transition in Pakistan
}

\author{
Taqi Raza ${ }^{\text {a }}$, Nabila Asghar ${ }^{\text {b }}$, Farhat Rasul ${ }^{\text {c }}$ \\ ${ }^{a}$ PhD Scholar, Pakistan Institute of Development Economics (PIDE), Islamabad, Pakistan \\ Email: taqi.pide@gmail.com \\ ${ }^{\mathrm{b}}$ Assistant Professor, Department of Economics and Business Administration, Division of Arts and Social \\ Sciences, University of Education Lahore, Pakistan \\ Email: nabeela.asghar@ue.edu.pk \\ ${ }^{c}$ Assistant Professor, School of Business and Economics, University of Management and Technology, \\ Lahore, Pakistan \\ Email: fahat.rasul@umt.edu.pk
}

\begin{tabular}{l}
\hline ARTICLE DETAILS \\
\hline History: \\
Accepted o5 March 2021 \\
Available Online 31 March 2021 \\
\\
\hline Keywords: \\
Demographic Transition, Labour \\
Force, Pension Expenditures, and \\
Growth Accounting
\end{tabular}

JEL Classification:

J11, J21, H55, R11

DOI: $10.47067 /$ reads.v7i1.320

\begin{abstract}
This study has examined the fiscal impacts of the demographic transition. Declining fertility rate and increasing life expectancy rate are expected to cause ageing in Pakistan. The population projections of United Nation's World Population Prospects were used, for projecting the labour force, which uses different scenarios to project population namely low variant, medium variant and high variant scenario. The study found that projected labour force is expected to decline under the medium variant scenario. The study examined the impact of expected decline in labour force on output growth of Pakistan using growth accounting technique, and found that under medium variant scenario, Pakistan is expected to face a loss of $4 \%$ of GDP at the end of this century. On the expenditure side, this study attempted to measure the impact of demographic transition on pension expenditures. Due to the increase in the proportion of the dependent population pension expenditures are expected to rise from $1.2 \%$ of GDP in 2015 to $3.5 \%$ of GDP by the end of the century. Due to the increase in old-age dependency ratio and hike in pension expenditures of Pakistan pay-asyou-go pension system is expected to become fiscally unsustainable as fewer workers would be bearing the burden of aged population. This fact advocates transition from pay-as-you-go pension system to fully funded pension system.
\end{abstract}

(C) 2021 The authors. Published by SPCRD Global Publishing. This is an open access article under the Creative Commons AttributionNonCommercial 4.0

Corresponding author's email address: taqi.pide@gmail.com

\section{Introduction}

Research based on the issues related to demographic transition gained importance in developed countries, such as Japan, Korea and most of the European Union countries, when they started facing the transition (Pestieau, et al., 2008; Galasso \& Profeta, 2004). Learning from their experience developing 


\section{Review of Economics and Development Studies, Vol. 7 (1) 2021, 37-50}

countries should also start putting efforts to tackle the issues relating to demographic transition before it becomes very difficult to manage effectively. Like most of the developing countries Pakistan too has a youth bulge also known as the potential demographic dividend, which refers to a process where rate of population growth in working ages is higher than the growth rate of total population. Due to higher life expectancy rates, after a certain period of time, this bulge is going to enter into unproductive ages, which will put added economic burden on the society if not managed properly (Durr-e-Nayab, 2008).

Demographic structure changes due to mainly two reasons; low fertility rate and increasing life expectancy rate. Due to lower fertility rates, the number of children born each year decreases and in the long run this ultimately reduces the workforce. Two of the main reasons of lower fertility rates are women's involvement in education and their increasing participation in the workforce (Orubuloye, 1991). As the policy makers would like to increase both factors in future so fertility rates are expected to decrease. Lower fertility rates are also due to success of the family planning schemes. According to the United Nation's World Population Prospects (Nations, 2015) average fertility rate for Pakistan in 20102015 decreased to 3.72 from 6.60 in $1950-1955$ and is projected to reduce further to 1.83 in $2095-2100$.

The second reason for population ageing is rising life expectancy rates due to better health facilities. And as we all want to improve it further, the population is going to get older. According to Nations (2015) average life expectancy rate for Pakistan in 2010-2015 increased to 65.88 from 37.07 in 1950-1955 and is projected to rise further to 79.04 in 2095-2100. These statistics indicate the forthcoming transition in the population structure of Pakistan.

Ageing population causes increase in old-age dependency ratio i.e. ratio between population aged $60+$ and population between 15 \& 6o. Increase in this ratio means that share of dependent population (aged 6o+) increases i.e. there are fewer people who will have to take responsibility of the aged population. According to the Nations (2015) old-age dependency ratio for Pakistan is expected to increase in 2095-2100 to 31.8 from 7.4 in 2010-2015. This increase will test policymaking and put pressure on the government resource bodies regarding financing of social security schemes for these elderly people. Financing pension expenditures comes directly under fiscal policy heads. Fiscal expenditures such as pension expenditures are directly affected by demographic changes. This study will try to quantify the implications of population ageing on these pension expenditures.

Other than old-age dependency ratio, another way of showing the demographic structure is through population pyramid, also known as age-sex pyramid. Dividing population into different age segments can give us a clear picture of country's population entering and exiting the working force (Kitao, 2015). 
Figure 1: Population Pyramids of Pakistan; Age-SeX Structure in 2015

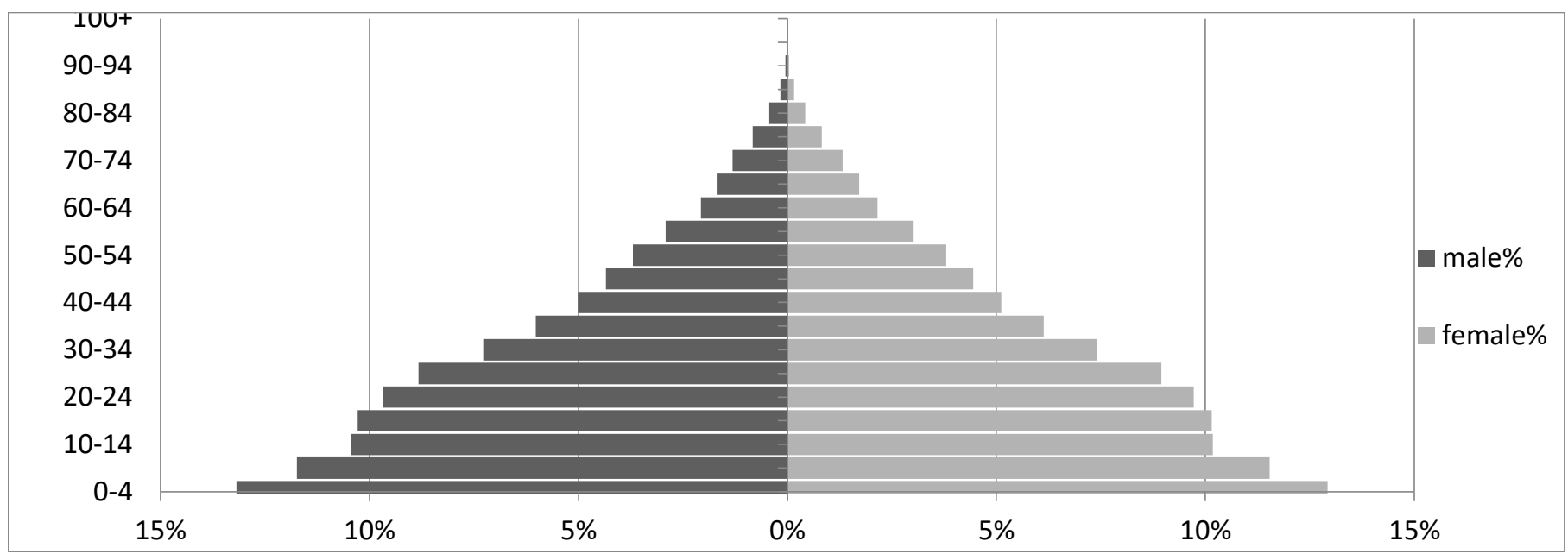

Source: UN’s World Population Prospect 2015

Figure 2: Population Pyramids of Pakistan; ExPected Age-Sex Structure in 2100

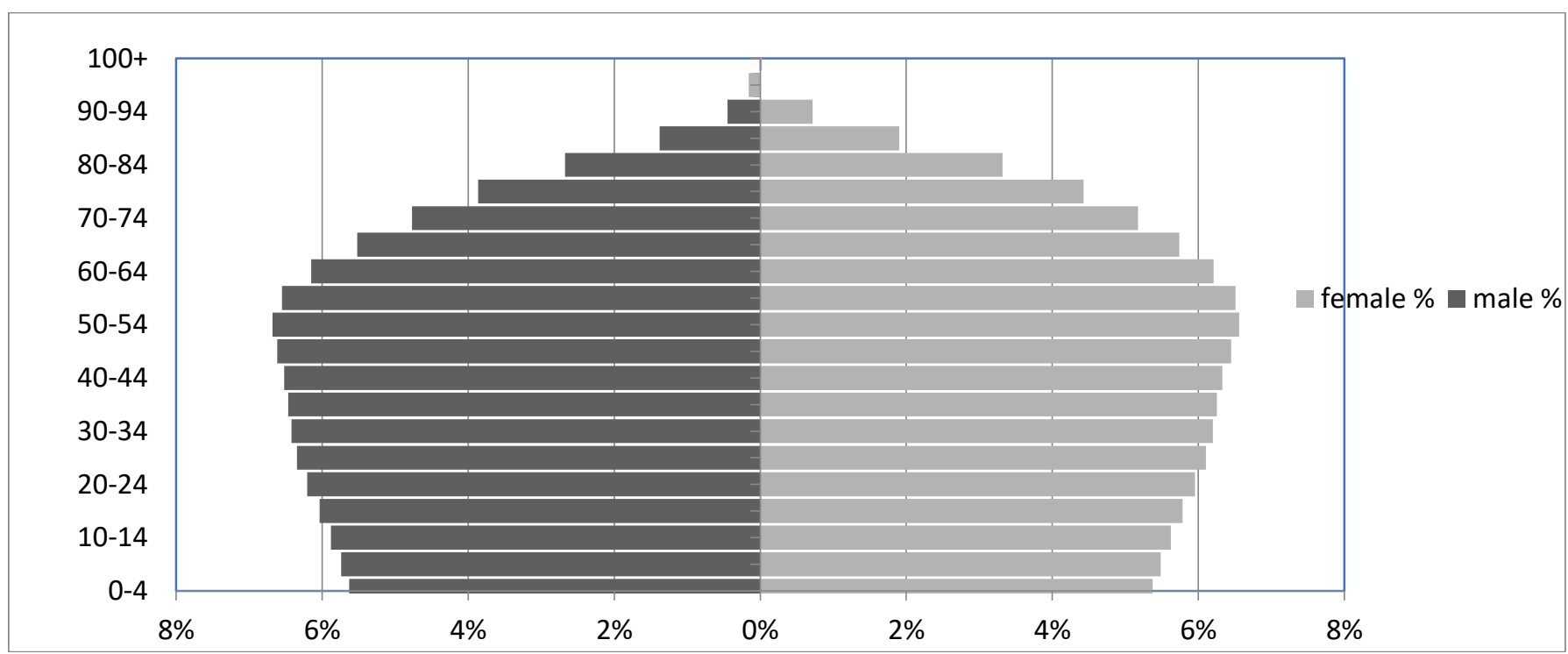

Source: UN’s World Population Prospect 2015

Figure 1 shows the age-sex structure of population of Pakistan. From figure 1 we can see that working age population is in higher proportion than the non-working age population in 2015. This represents a positive sign for the Pakistan's economy to utilize this potential youth bulge for the betterment of future. If this opportunity is not utilized properly we will face a different situation as presented in Figure 2. The figure explains that in 2100 we will have higher proportion of population in non-working age which will burden the economy and put fiscal pressure on the government.

As demographic transition is expected to happen, it is important to study and investigate its possible economic consequences Ageing of population can cause fiscal imbalances from both revenue and expenditure sides (Yoon, et al., 2014). The loss in revenues can be examined through measuring loss in the GDP. There are theories that regard increasing population as a burden, while there are also theories that regard shrinking population as a threat to economic growth. A more moderate view, 


\section{Review of Economics and Development Studies, Vol. 7 (1) 2021, 37-50}

however, is that it is not the number but the structure of population that really matters. Ageing of population means more people will enter into non-working class compared to working class. GDP may not be directly affected by ageing but the size of working class in a country is a determinant of its GDP. It affects the national output according to the Solow growth model (Solow, 1956). In the Solow growth model, at steady state, long term output is directly proportional to population or labour-force growth rate. So it becomes important to quantify the long term cost in terms of loss in GDP due to ageing.

On the expenditure side, this study focuses on the pension expenditures of Pakistan as these expenditures are more likely to be affected when the transition takes place. In most of the countries, including Pakistan, pension system is controlled by the government in which currently working population is taxed to pay for the pensions of retirees. This system is known as pay-as-you-go (PAYG) pension system. But as the demographic transition is going to take place, fewer workers will have to bear the burden of larger old population due to increasing old age dependency ratio. Therefore, there is a need to reassess this pension system. Also pension system and formal social security system benefit workers employed in formal sector mostly and specifically employed in the government sector. This calls for reassessment of the social security and pension systems.

An alternative to this system is fully funded pension system in which the workers are taxed a particular amount from their income which is invested by government. Returns from that investment are then given to the same workers when they retire according to their invested amount. Our objective is to try to quantify the fiscal cost of pension expenditures under the PAYG system, which is currently the pension system in Pakistan. Under this system, pension expenditures are expected to rise given the ageing of population takes place (Amaglobeli \& Shi, 2016). With the demographic transition, ratio between pension receivers and workers is rising and in future workers will be taxed more than today in order to provide the same standard of living to the dependent population hence in coming decade's payas-you-go system will become fiscally unsustainable due to the demographic transition (Arif \& Ahmad, 2010).

The expected population rebalancing and accompanying surge in age-related spending, which lower economic growth will likely place considerable pressure on public finances going forward. While the near-term fiscal effects of these demographic developments are likely to be small, their long-term fiscal implications are significant. Therefore, researchers and policymakers, in countries affected by adverse demographic dynamics, need to quantify fiscal risks from demographic developments ahead of time. Objective of this study is to quantify fiscal implications of the ageing population. This includes measuring impacts of the following (a) Demographic transition on the GDP growth rate and (b) Changes in old-age dependency ratio on pension expenditures.

\section{Literature Review}

At the start of the $2 \mathrm{O}^{\text {th }}$ century, transition in birth, fertility and mortality rates started and hence the term demographic transition was coined for the first time by Warren S. Thompson and explored by Frank W. Notestein. Reasons associated with high fertility rates were religious and moral and customs prevailing in societies, like early marriages. With decline in mortality rates and increasing educated proportion in population, social norms that supported high fertility rates were no longer required (Orubuloye, 1991; Sanderson \& Scherbov (2007). Caldwell (1976) has dictated two main factors that strengthen the transition from high to low fertility rates, which are education and urbanization. He is of the view that these two factors have impact on family relations and thus on fertility rate too. Lee \& Edwards (2002) stated that lower fertility is one of the two main reasons attributed to ageing of population. 


\section{Review of Economics and Development Studies, Vol. 7 (1) 2021, 37-50}

In Asia, the importance of research based on ageing gained attention in 1980s when countries like Malaysia, Taiwan, Japan and Singapore started facing it. It is expected that, by and large, the ratio of aged population in Asia is going to rise to $21 \%$ in 2030 (Chan, 1999). Pakistan is also on the way to ageing of population as its mortality and fertility rates have started to decline and increase in mean and median life of population is an indicator of ongoing transition (Mahmood \& Nasir, 20o8).

Demographic transition causes old-age dependency ratio to rise due to decline in fertility rate and surge in life expectancy rate. Pampel (1994) investigated the political pressure of ageing using data of 18 advanced economies for the period from 1959 to 1986. He argued that ageing puts pressure on public spending because of certain demographic and political reasons, which gives rise to age-based inequality in public spending. Auerbach \& Kotlikoff (1992) found that changing population structure affects political power of elderly population. In 2040 USA will have $42 \%$ of its population above 55 years of age so elderly population is going to have powerful political voice.

Analyzing the effects of ageing on macroeconomic variables, Yoon, et al., (2014) found that inflation is affected by changes in aggregate demand due to change in age structure while output changes due to changes in labour-force participation rate which again is dependent on population size and structure at a particular time. Harvard School economists argue that what really matters is age structure rather than its size (Hugh, 2009). Impact of ageing on economic growth through changes in labour force participation is discussed in literature (clements, 2015). Kudrna, et al., (2015) developed an Over-Lapping Generation model for investigating the effects of demographic shift in Australia. Expected results showed demographic transition caused 6.2\% decline in GDP per capita, surge in capitaloutflows and less investment opportunities in the future.

Di Matteo (2010) stated that ageing is viewed as a variable responsible for rising wellbeing expenditures, though in Canada its effect is comparatively smaller than other variables. Palacios (1996) investigated the variables on which pension expenditures depend. They found that ageing has a significant impact on pension expenditures and this effect is stronger than income per capita, which means that increase in per capita income also causes an increase in pension expenditures but not as much as ageing does. Pampel, et al., (1990) argued that data shows, that these expenditures have surged even when countries were facing fiscal problems. Lee \& Edwards (2002) in their analysis found that expenses on elderly population are going to increase from $8 \%$ of GDP today to $21 \%$ of GDP in future. Kitao (2015) stated that Japan's economy may restrain as it is going to face an expansion in public expenditure with less working force in the future and less revenue. In wake of these fiscal imbalances methods of funding the expenses on pension and health care and policies related to retirement decisions are required to be modernized (Fogel, 1997).

The ageing of population in Pakistan is bound to put pressure on policymakers to reform the social security system. It also questions the quality of life of poor and elderly in wake of present system which covers only government employees and a very minor proportion of private employees in formal sector whereas informal sector remains out of reach. Mahmood \& Nasir (2008) stated that in Pakistan, social security and pension schemes sponsored by the government benefit a small proportion of the population in the formal sector. Pakistan needs to redefine the budget priorities keeping in view the proportion of population engaged in the informal sector. According to Arif \& Ahmed (2010) current resources allocated to pensions are not only small in numbers but are inadequate to fulfill the need of rising proportion of older population. It is estimated that if proper measures are not taken than pension expenditure can increase to three percent of GDP (Mahmood \& Nasir, 2008). This section concludes that ageing has significant impact on GDP through changes in labour-force participation and it alters 
political power of elders and causes surge in spending related to older population.

\section{Methodology and Data}

Demographic transition has a two-way effect on fiscal balances, i.e. effect on revenues as well as on expenditures. The revenue effect is quantified through changes in GDP (national income) due to demographic transition. Expenditure side is affected by changes in pension expenditure because of ageing population.

\subsection{Growth Accounting}

Demographic transition alters the structure of population which affects labor force due to which the economic environment changes. Effect of the demographic transition, specifically the effect of ageing population, on growth is quantified using the Cobb-Douglas production function. Accounting framework is used because we can apply appropriate restrictions/assumptions, based on economic theory, on other variables and then change the variable in question to assess its impact on output (Barro, 1991). Also we can calculate TFP by separating it from other inputs of growth using accounting framework (Griliches and Jorgenson, 1967). Moreover, Solow model of economic growth has highest explanatory power (Mankiw et al, 1992). Assumption of constant returns to scale in production function is applied as there is no empirical evidence of increasing returns to scale and in decreasing returns to scale, one has to explain the increasing share of wages in total income (Solow, 1956, Mankiw et al, 1992).

The Cobb-Douglas production function is specified as follows:

$$
Y_{t}=\operatorname{TFP}_{t} \times K_{t}^{1-\beta} \times L_{t}^{\beta} \quad \ldots \cdots \cdots \cdots \cdots \cdots \cdots
$$

Where, $\mathrm{Y}_{\mathrm{t}}$ is GDP over time. $\beta$ is labour's share in total income. Following Khan (2006) we assume values for factor income shares to be 0.56 for labour and 0.44 for capital.

\subsubsection{Capital Stock}

$\mathrm{K}_{\mathrm{t}}$ is capital stock. Capital stock is calculated using perpetual inventory method (Berlemann and Wesselhoft, 2014) using the following equation,

$$
K_{t}=(1-\delta) K_{t-1}+I_{t} \ldots \ldots \ldots
$$

According to equation 3.2 capital stock in any year is the sum of previous year's capital and net investment. But for this we need to calculate initial value of capital stock to be able to generate a time series for capital stock based on that initial value, new investment and depreciation rate. The issue of how to calculate initial value of capital stock has been debated long in literature. There are many approaches to calculate capital stock, but we have used the unified approach, as used by Berlemann and Wesselhoft (2014). Other methodologies like steady state approach, the disequilibrium approach and the synthetic approach have their peculiar requirements and related shortcomings which made them unviable for the present study. The unified approach combines the positive points of different methodologies (Berlemann and Wesselhoft, 2014). It follows De La Fuente \& Domenech (2006) for measuring initial value of capital stock.

$$
K_{t-1} \approx \frac{I_{t}}{g^{I}+\delta}
$$


Review of Economics and Development Studies, Vol. 7 (1) 2021, 37-50

But this approach deviates in measuring the value of $I_{t}$ for $t=1$. They used investment data from $\mathrm{t}=2$ to $\mathrm{T}$ and regressed it on time trend to measure initial value of investment. Equation for the regression can be written as,

$$
\ln I_{i t}=\alpha_{i}+\beta_{i} \cdot t+\varepsilon_{i t}
$$

By using the parameters $\alpha$ and $\beta$ we can calculate the fitted value of investment for $t=1$. Then this value is used to measure the initial value of capital stock. Berlemann and Wesselhoft (2014) deviate in another way in that they used time series of depreciation rate instead of assuming constant rate of depreciation. Because of the relative benefits of Berlemann and Wesselhoft (2014) we opted for their methodology for measuring initial value of capital stock. We calculated values for 3 years instead of 1 and then took average of the three to get initial value for capital stock following Berlemann and Wesselhoft (2014). Once this value was obtained we generated capital series using Equation 3.2.

\subsubsection{Aggregate Labour}

To estimate aggregate labor, historical labor force participation rates and employment rates are used. Also the size of each age-gender specific cohort and actual hours worked by labor are used to calculate aggregate labour force. The aggregate labour force is estimated using equation $3 \cdot 3$, following Clements (2015), given below.

$$
L_{t}=\sum_{J=1}^{j} N_{t}^{j} \times L F P_{t}^{j} \times E_{t}^{j} \times w_{t}^{j} \quad \ldots \ldots \ldots \ldots \ldots \ldots
$$

Where, $\mathrm{j}$ represents age-gender cohort, $\mathrm{N}$ and LFP are number of people and labor force participation rate in a specific cohort, respectively, $\mathrm{E}$ is employment rate, and $\mathrm{w}$ is weight factor for the adjustment between number of employees and effective units of labor. When we multiply this weight factor, we get labour force in number of work hours supplied instead of number people currently working. This is a better measure of labour force as it explains GDP in a better way according to the standard definition of contribution of labour force in GDP (Clements 2015). Final labour force is calculated by adding labour hours provided by different age groups. Taking logarithm of Equation 3.1 and substituting the value of $K_{t}$ and $L_{t}$ it becomes,

$$
\ln Y_{t}=\ln T F P_{t}+(1-\beta) \ln K_{t}+\beta \ln \sum_{J=1}^{j} N_{t}^{j} \times L F P_{t}^{j} \times E_{t}^{j} \times w_{t}^{j} \ldots \ldots \ldots
$$

\subsubsection{Total Factor Productivity}

Equation 3.4 is used to measure historical TFP, which is given by:

$$
\ln T F P_{t}=\ln Y_{t}-(1-\beta) \ln K_{t}-\beta \ln \sum_{J=1}^{j} N_{t}^{j} \times L F P_{t}^{j} \times E_{t}^{j} \times w_{t}^{j} \ldots \ldots \ldots
$$

After this step we arrive at historical TFP, labor and capital data. Following Clements (2015), to capture the output effect due to changes in labour force through ageing of population, we use the assumption that total factor productivity is expected to grow at its historical level while capital is expected to follow balanced growth condition (Amaglobeli and Shi, 2016). These assumptions are used so that we can check the impact of change in labor force only, keeping other factors constant. Using 
these assumptions on TFP and capital, different demographic transition scenarios give rise to different labor force and hence different GDP projections.

\subsection{Pension Expenditures}

Following Clements (2015), pension expenditures to GDP ratio is derived by multiplying four factors, which are replacement rate, coverage ratio, inverse of labor force participation rate and old-age dependency ratio. Mathematically,

$$
\frac{P E}{G D P}=R . R \times C . R \times O D R \times \frac{1}{L P} \quad \ldots \ldots \ldots \ldots
$$

Where PE is pension expenditures; R.R is replacement rate defined as ratio between average pension and average output, C.R is coverage ratio defined as share of pensioners in total population above 6o; ODR is old-age dependency ratio defined as ratio between dependent population above 6o and working age population (15-60); and LP is labor participation rate defined as share of workers in working age population. Mathematically, each term is defined as:

$$
\begin{array}{ll}
R . R=\frac{\text { average pension }}{\text { average output }}=\frac{\frac{P . E}{\text { Pensioners }}}{\frac{\text { GDP }}{\text { Workers }}} & C . R=\frac{\text { Pensioners }}{\text { Population } 60^{+}} \\
O D R=\frac{\text { Population } 60^{+}}{\text {Population 15-60 }} & L P=\frac{\text { Workers }}{\text { Population 15-60 }}
\end{array}
$$

\subsection{Data and variable description}

Time series data for Pakistan is gathered from 1981 to 2015. Data for GDP (in constant Pak rupees) and gross fixed capital formation (in constant Pak rupees) have been collected from the World Development Indicators (WDI). Time series data on depreciation rate (in percentage terms) of capital is taken from Penn World Tables 9.o. Data on labour is aggregated using population, employment rate (in percentage terms), labor force participation rate (in percentage) and a weight factor to adjust for productivity of labour. Data on population is collected from the United Nation's World Population Prospects (Nations, 2015) while labour force participation rate, employment rate, and work hours (number of hours per week) are available from the Labour Force Survey (LFS). For expenditure analyses, data on the pension expenditures (in constant Pak rupees) and number of pensioners is collected from the Accountant General Pakistan Revenue (AGPR), Ministry of Finance.

\section{Results and Discussions}

\subsection{Impact on the Labour Force:}

Different demographic scenarios will produce different levels of population and hence different labour force trends. Based on the projections made, using high, medium, low and status quo scenarios, Figure 3 explains the trend in labour force under medium variant scenario. As can be seen from Figure 3 , there is an increasing trend in labour force for the next two decades or so under both scenarios (status quo and medium variant). After 2040, the labour force, under medium variant scenario, deviates from the labour force under status scenario due to demographic transition. Under medium variant scenario, it reaches its maximum value around 2080 and declines thereafter. Reason for increase in labour force in the projection period from 2015 to around 2060 is increasing population in that period under both the scenarios. 


\section{Figure 3: Projected Labour Force (Million Work Hours)}

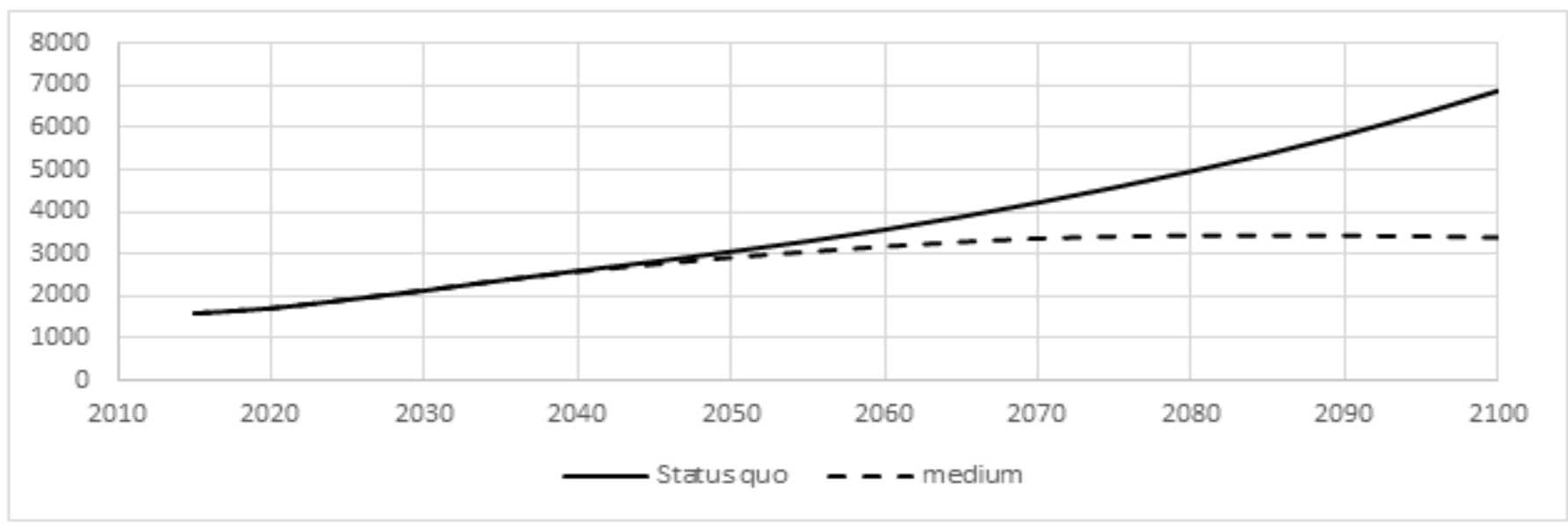

Source: Authors' Own Calculations

The fertility rate of Pakistan is expected to be above the replacement level, which is 2.1 children per woman, which means until 206o people entering the population will be greater than the people exiting the population. This leads to rising population. Also, improvement in life expectancy rate will raise the median year of age. These factors will raise population and hence the labour force. Around 2060 fertility rate touches replacement level so people entering the population and exiting from it will be equal at this point and hence population will touch its maximum value and so does labour force as depicted in the above figure. Decline in labour force starts afterwards due to decline in population. The other factor, life expectancy rate, improves as time passes and population starts ageing. As aged population has lower labour force participation rate, lower employment rate and fewer work hours so, these factors will play part in lesser labour force under medium variant scenario compared to the status quo scenario.

The status quo scenario (solid line) shows labour force in case when there is no change in fertility rate and life expectancy rate from the 2015 level. It means that under status quo scenario population will continue to grow at constant rate. Although this scenario is highly unlikely to occur but it provides us a reference point with which we can compare the projected labour force under medium variant scenario. Given the projections under medium variant scenario labour force will initially affect output positively as increasing labour force will lead to higher output. But after reaching its maximum point, i.e. after 2060 , and its decline will start to harm the output, other factors like total factor productivity and capital remaining the same. Projections under other scenarios (low variant, and high variant) are presented in Figure 4. 
Figure 4: Projected Labour Force (Million Work Hours)

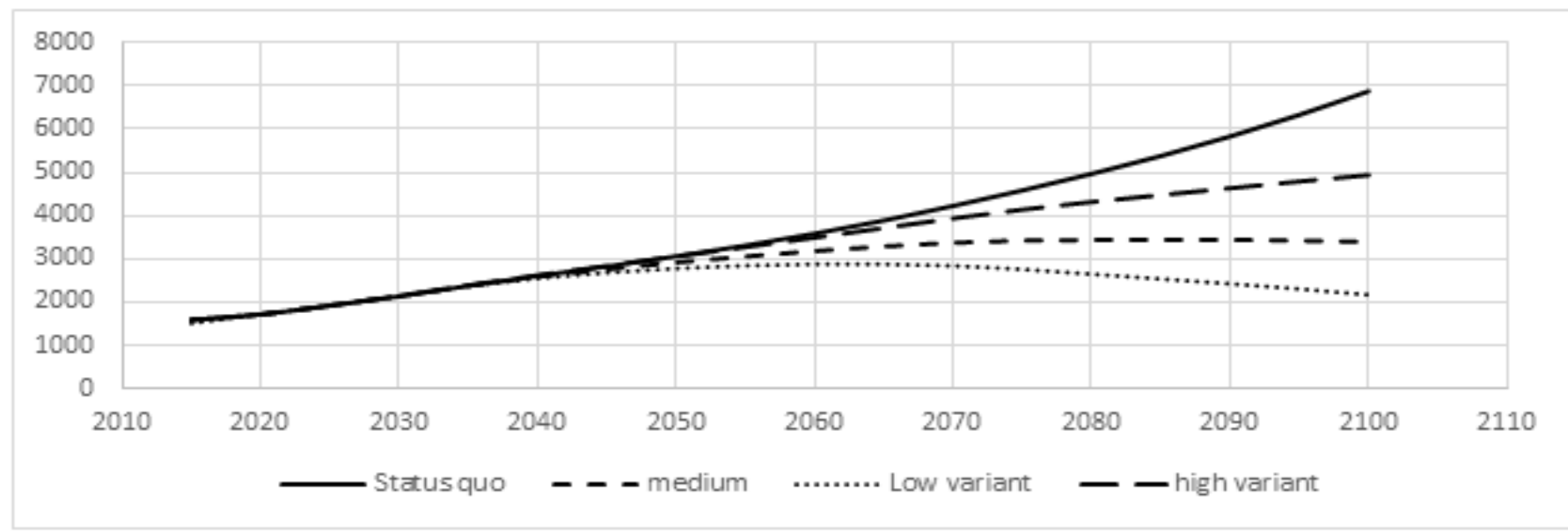

Source: Authors' Own Calculations

\subsection{Impact on Output}

This section explains the impact of demographic transition on the output (GDP) of Pakistan. Given the expected trend in the labour force, explained in the previous section, this section quantifies the effect of labour force trend on output. Labour force does change due to change in the age structure of population. So, keeping other factors constant, demographic variables are affecting the labour force which in turn is changing the level of output. These changes are explained with the help of Figure 5 .

\section{Figure 5: Projected GDP Growth Rate}

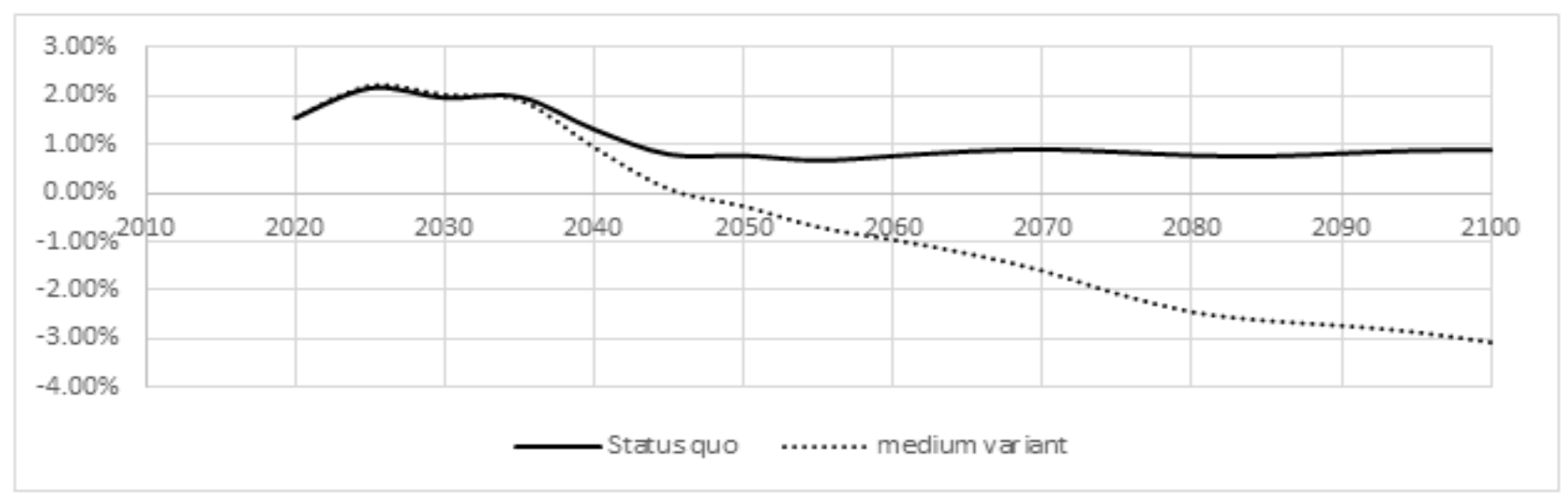

Source: Authors' Own Calculations

Figure 5 shows that the annual output growth rate is expected to decline to as low as $-3.1 \%$ under medium variant whereas economy grows at $1 \%$ growth rate under status quo scenario. It means around $4.1 \%$ loss in GDP is expected only because of the demographic transition. Demographic factors will be dampening the positive affect of other factors, such as improvement in productivity. Figure 6 presents difference in growth rates from status quo scenario under other scenarios. 
Figure 6: Output Comparison Under Different Scenarios

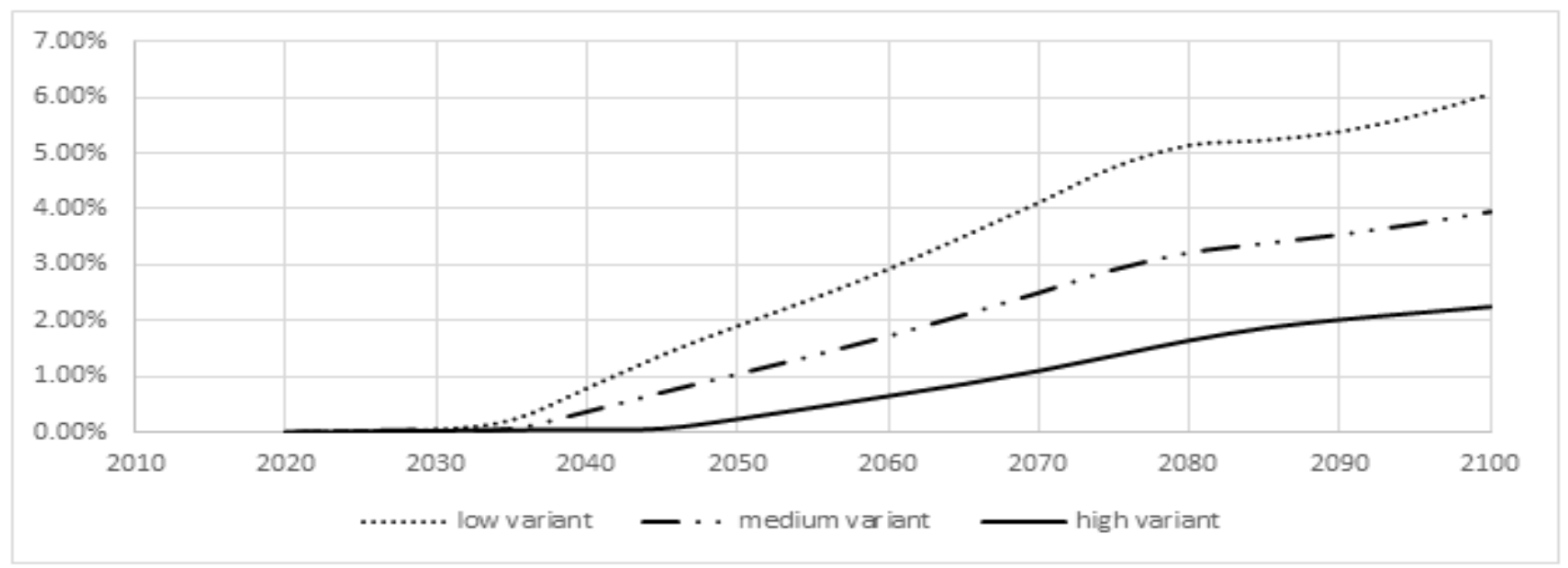

Source: Authors' Own Calculations

\subsection{Impact on Pension Expenditures}

This section explains the impact of demographic transition on pension expenditures of Pakistan. Given the recent trend of pension expenditures we can say that pension expenditures are rising over time. One of the two reasons of this rise is that number of pensioners is increasing and the other reason is increase in pension expenditures per person due to inflation. As the growth rate of pension expenditure $(12.9 \%)$ is greater than growth rate of GDP $(4.2 \%) 1$, the ratio of pension expenditures to GDP (Pension Expenditures/GDP) is expected to increase anyway. But what this study is trying to capture is the effect of demographic transition on pension expenditures. Due to increasing pension expenditures per-pensioner, replacement rate (R.R) is expected to rise, so is the coverage ratio (C.R) as the number of pensioners is rising. Now this increase in replacement rate and coverage ratio will put pressure on pension expenditures and an upward trend in pension expenditures is expected. To capture the demographic effects only, following Clements (2015), we are assuming it to be constant at the 2015 level throughout the projection period.

Table 1: Replacement Rate and Coverage Ratio of Pakistan

\begin{tabular}{|l|l|l|l|l|l|l|l|l|}
\hline Year & $\mathbf{2 0 0 8}$ & $\mathbf{2 0 0 9}$ & $\mathbf{2 0 1 0}$ & $\mathbf{2 0 1 1}$ & $\mathbf{2 0 1 2}$ & $\mathbf{2 0 1 3}$ & $\mathbf{2 0 1 4}$ & $\mathbf{2 0 1 5}$ \\
\hline R.R & 0.0342 & 0.0464 & 0.0563 & 0.0599 & 0.0825 & 0.0981 & 0.1026 & 0.1062 \\
\hline C.R & 0.1386 & 0.1395 & 0.1438 & 0.1453 & 0.1455 & 0.1449 & 0.1622 & 0.1751 \\
\hline
\end{tabular}

Source: Authors' Own Calculations

Table 1 exhibits the replacement rate (R.R) and coverage ratio (C.R) in different years. Both ratios are increasing with time. In 2015 replacement rate (R.R) was 0.11, which means that, on average, $11 \%$ of young workers' share in GDP goes to a pensioner if Pakistan is running pay-as-you-go pension system (a system in which pension expenditures are borne by currently working population). Coverage ratio (C.R) in 2015 was 0.17 . It means that $17 \%$ of total population above 60 is receiving pension benefits from the government.

The other two variables of our interest included in the definition of pension expenditures, are old-age dependency ratio (ODR) and labour participation (LP). The demographic transition will affect 


\section{Review of Economics and Development Studies, Vol. 7 (1) 2021, 37-50}

both these variables. In turn, these variables will affect pension expenditures. Old-age dependency ratio is expected to increase as the population above 60 is expected to last longer due to better health facilities and population between ages 14 and 60 is expected to shrink due to declining fertility rate. Given these two transitions in the demographic structure of Pakistan, the old-age dependency ratio will rise and in turn it will increase pension expenditures according to Equation 3.6. Given these changes in the demography of Pakistan, pension expenditures are expected to rise. Projections regarding pension expenditures are shown in Figure 7. We can see that pension expenditures to GDP ratio shows a rising trend throughout the projection period. Starting from just 1.2\% of GDP in 2015, pension expenditures are expected to rise to $3.5 \%$ of GDP by the end of century (under medium variant scenario).

\section{Figure 7: Projected Pension Expenditures (\% of GDP)}

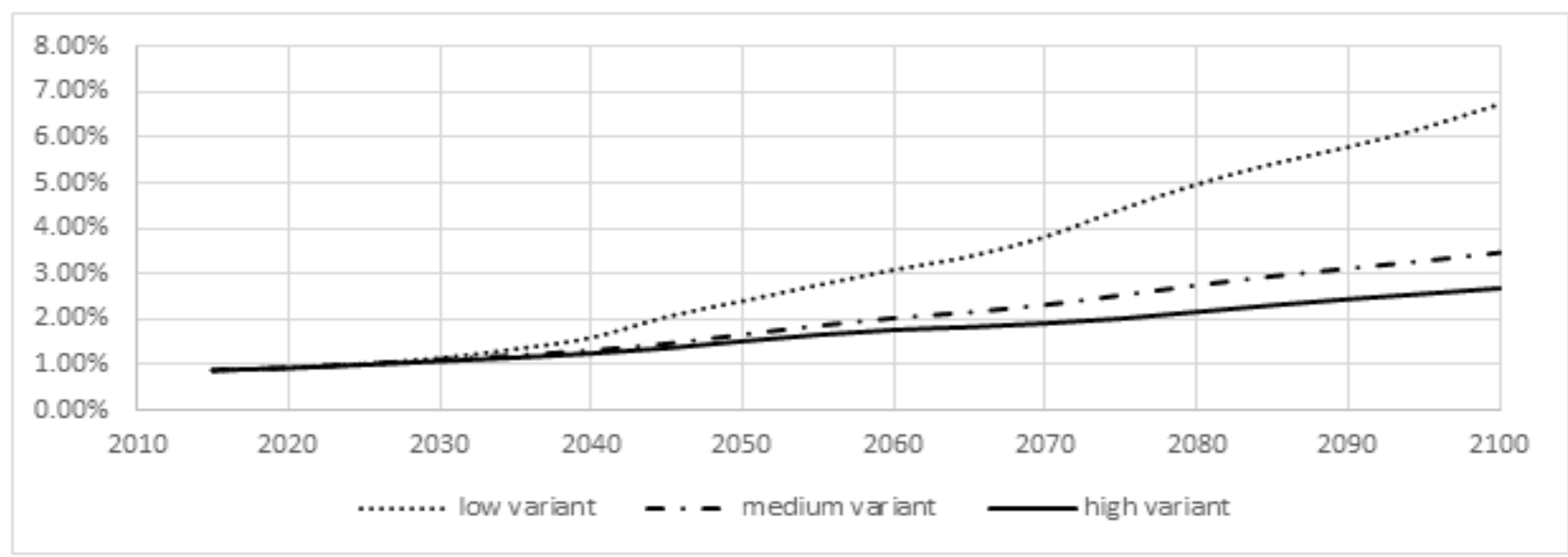

Source: Authors' Own Calculations

Up till 2040-45 the increase in pension expenditures is mainly because of increase in old-age dependency ratio. Decline in labour force starts after 2045 so after that old-age dependency ratio would play its part in increasing pension expenditures as share of GDP. Due to this pension expenditures are expected to rise to $3.5 \%$ of GDP at the end of the projection period. These rising expenditures advocate for fully funded pension system instead of pay-as-you-go pension system. When pension expenditures increase due to increase in old-age dependency ratio conventional pay-as-you-go pension system becomes fiscally unsustainable as there would be fewer workers bearing the burden of a larger aged population. To finance the rising expenditures, under pay-as-you-go pension system, either government will have to allocate more resources on pension expenditures or high payroll taxes would be required from working population for covering the expenditures. While switching to fully funded pension system will not only save a fortune to government, but workers will also contribute happily as the contribution would be invested on their behalf for their safe future.

\section{Conclusion}

The present study has tried to quantify the fiscal impacts of the demographic transition in Pakistan. Population projections by Nations (2015) have been used to project the labour force in Pakistan from 2015 to 2100. Due to declining fertility rate and increasing life expectancy rate old-age dependency ratio is expected to increase, which means aged population - which has lower labour force participation rate, employment rate and work hours - would increase more than the working age population. This study found that Pakistan is expected to face a decline in its work force in the long run. Based on the Nations (2015) fertility rate is expected to be above replacement level until 206o which means population will continue to grow at a slower pace but then population as well as labour force is 
expected to shrink.

This study has also attempted to quantify the effect of expected decline in the labour force on GDP growth rate, which was done using the growth accounting technique, based on the Cobb-Douglas production function. Output was also measured under both status quo and medium variant scenarios. According to the findings of the study, under the medium variant scenario Pakistan is expected to face a $4 \%$ loss in GDP by the end of century only because of the demographic transition.

On the expenditure side, this study has tried to measure the impact of demographic transition on pension expenditures. Due to increase in old-age dependency ratio the proportion of dependent population is increasing more than younger population. This study found that if Pakistan continues to follow pay-as-you-go pension system then the pension system would become fiscally unsustainable due to expected ageing of population. Pension expenditures are expected to rise from $1.2 \%$ of the GDP in 2015 to $3.5 \%$ of the GDP in 2100 . And if these expenditures are to be borne by the future working age population then it will be fiscally unsustainable as there would be fewer workers who will bear the burden. So, the study suggests a transition from pay-as-you-go pension system to a fully funded pension system based on its findings. On the basis of above discussion the study concludes that if proper measures are not taken demographic transition is expected to harm the economy by lowering output as well as by increasing pension expenditures.

\section{Policy Recommendations}

According to the findings of the present study Pakistan is expected to face a decline in labour force. But the situation can be different if women's involvement in labour force is encouraged. Due to low female labour force participation rate in Pakistan the situation is looking not too bright. Similarly special attention must be paid on improving the total factor productivity as this will also help to weaken the negative impacts of demographic transition on output. Based on findings of this study it is suggested that a comprehensive study needs to be done to explore the transition from pay-as-you-go to fully funded pension system following the multi pillar pension reform provided by World Bank. Costs associated with transition also need to be explored.

\section{References}

Amaglobeli, M. D., \& Shi, W. (2016). How to Assess Fiscal Implications of Demographic Shifts:A Granular Approach. International Monetary Fund.

Arif, U., \& Ahmed, E. (2010). Pension system reforms for Pakistan: Current Situation and Future Prospects. Pakistan Institute of Development Economics.

Auerbach, A. J., \& Kotlikoff, L. J. (1992). The impact of the demographic transition on capital formation. The Scandinavian Journal of Economics, 281-295.

Barro, R. J. (1991). Economic growth in a cross section of countries. The Quarterly Journal of Economics, 106(2), 407-443.

Berlemann, M., \& Wesselhöft, J. E. (2014). Estimating aggregate capital stocks using the perpetual inventory method: A survey of previous implementations and new empirical evidence for 103 countries. Review of Economics, 65(1), 1-34.

Caldwell, J. C. (1976). Toward a restatement of demographic transition theory. Population and development review, 321-366.

Chan, A. (1999). The Social and Economic Consequences of Ageing in Asia: An Introduction. Southeast Asian Journal of Social Science, 27(2), 1-7.

Clements, M. B. J. (2015). The fiscal consequences of shrinking populations. International 
Monetary Fund.

De la Fuente, A., \& Doménech, R. (2006). Human capital in growth regressions: how much difference does data quality make?. Journal of the European Economic Association, 4(1), 136.

Di Matteo, L. (2010). The sustainability of public health expenditures: evidence from the Canadian federation. The European Journal of Health Economics, 11(6), 569-584.

Fogel, R. W. (1997). Economic and social structure for an ageing population, Philosophical Transactions of the Royal Society of London B: Biological Sciences, 352(1363), 1905-1917.

Galasso, V., \& Profeta, P. (2004). Lessons for an ageing society: the political sustainability of social security systems. Economic Policy, 19(38), 64-115.

Griliches, Z., \& Jorgenson, D. W. (1967). The explanation of productivity change. Review of Economic Studies, 34(3), 249-283.

Kitao, S. (2015). Fiscal cost of demographic transition in Japan. Journal of Economic Dynamics and Control, 54, 37-58.

Kudrna, G., Tran, C., \& Woodland, A. (2015). The dynamic fiscal effects of demographic shift: The case of Australia. Economic Modelling, 50, 105-122.

Lee, R., \& Edwards, R. (2002). The fiscal effects of population aging in the US: Assessing the uncertainties. Tax policy and the economy, 16, 141-180.

Mahmood, N., \& Nasir, Z. M. (2008). Pension and social security schemes in Pakistan: Some policy options (No. 22211). East Asian Bureau of Economic Research.

Mankiw, N. G., Romer, D., \& Weil, D. N. (1992). A contribution to the empirics of economic growth. The quarterly journal of economics, 107(2), 407-437.

Nations, U. (2015). World population prospects: The 2015 revision. United Nations Econ Soc Aff, 33(2), 1-66.

Nayab. (2008). Demographic Dividend or Demographic Threat in Pakistan? The Pakistan Development Review, 1-26.

Orubuloye, I. O. (1991). The implications of the demographic transition theory for fertility change in Nigeria. International journal of sociology of the family, 21(2), 161-174. Retrieved March 20, 2021, from http://www.jstor.org/stable/23029817

Palacios, R. J. (1996). Averting the Old-Age Crisis. World Bank Policy Research Working Paper, (1572).

Pampel, F. C. (1994). Population aging, class context, and age inequality in public spending. American Journal of Sociology, 100(1), 153-195.

Pampel, F. C., Williamson, J. B., \& Stryker, R. (1990). Class context and pension response to demographic structure in advanced industrial democracies. Social Problems, 37(4), 535550.

Pestieau, P., Ponthiere, G., \& Sato, M. (2008). Longevity, health spending, and pay-as-you-go pensions. Finanz Archiv: Public Finance Analysis, 64(1), 1-18.

Sanderson, W. C., \& Scherbov, S. (2007). A new perspective on population aging. Demographic research, 16(2), 27-58.

Solow, R. M. (1956). A contribution to the theory of economic growth. The Quarterly Journal of Economics, 70(1), 65-94.

Yoon, M. J. W., Kim, M. J., \& Lee, J. (2014). Impact of demographic changes on inflation and the macroeconomy (No. 14-210). International Monetary Fund. 